\title{
Image Processing and Analysis in Biomechanics
}

\author{
João Manuel R. S. Tavares and R. M. Natal Jorge \\ Faculty of Engineering, University of Porto, Rua Dr. Roberto Frias, s/n 4200-465 Porto, Portugal \\ Correspondence should be addressed to João Manuel R. S. Tavares, tavares@fe.up.pt
}

Received 16 December 2009; Accepted 16 December 2009

Copyright () 2010 J. M. R. S. Tavares and R. M. Natal Jorge. This is an open access article distributed under the Creative Commons Attribution License, which permits unrestricted use, distribution, and reproduction in any medium, provided the original work is properly cited.

Computational methodologies of signal processing and analysis based on 1D-4D data are commonly used in different applications. In particular, image processing and analysis methodologies have enjoyed increasing deployment in automated recognition, human-machine interfaces, computeraided diagnostics, robotic surgery, and many other areas; however, in the last years their application in Biomechanics has gained special attention.

This issue of the EURASIP Journal on Advances in Signal Processing constitutes the special issue related with Image Processing and Analysis applied to biomechanical systems, including data compression, data fusion, image segmentation, image registration, objects recognition, objects modeling, tracking and motion analysis, shape reconstruction, $3 \mathrm{D}$ vision, and virtual reality. One important feature to retainment of this special issue is the interdisciplinary of works resulting from the collaboration between mechanical engineers, electrical engineers, biomedical engineers, medical doctors, computational engineers, biologists, physicians, mathematicians, among others.

The success of this special issue is directed and associated with the high significance on analysis and simulation of biomechanical structures from images and their challenging problems, regarding geometric modeling, numerical modeling, material models and experimental methodologies, as well as their real application and validation. This great interest has been revealed by users, students, researchers, and all who are interested on areas related with signal processing, image processing and analysis, medical imaging, computational and experimental biomechanics, enhanced computation, and software applications.

For this special issue, 31 works were submitted from 18 countries: Belgium, Brazil, Canada, China, Croatia, Czech Republic, France, India, Iran, Ireland, Italy, Japan, Morocco,
New Zealand, Spain, Taiwan, Tunisia, and USA. After the review done by 55 international experts, 19 works were accepted for publication.

The guest editors would like to express their deep gratitude to the Editor-in-Chief and Associate Editors of EURASIP Journal on Advances in Signal Processing for this opportunity, to all authors that shared their excellent works with us and to all members of the Scientific Committee of this special issue that help us in the review process.

João Manuel R. S. Tavares R. M. Natal Jorge 